\title{
Do the seeds of Solidago gigantea Aiton have physiological determinants of invasiveness?
}

\author{
Anna Bochenek ${ }^{1} \cdot$ Agnieszka Synowiec $^{2} \cdot$ Bożena Kondrat $^{1} \cdot$ Milena Szymczak $^{1} \cdot$ \\ Lesław B. Lahuta ${ }^{1} \cdot$ Janusz Gołaszewski $^{3}$
}

Received: 18 September 2015/Revised: 19 April 2016/Accepted: 20 May 2016/Published online: 1 June 2016

(C) The Author(s) 2016. This article is published with open access at Springerlink.com

\begin{abstract}
Solidago gigantea Ait. (goldenrod) belongs to the most expansive environmental weeds, and it is the most dangerous plant-invader of American origin in Europe. The species easily propagates vegetatively, but it also produces large amounts of wind-disseminated achenes that contribute to the colonization of new areas. A sound knowledge of the germination biology of goldenrods is required to control the spread of this invasive species. The objective of this study was to investigate selected aspects of germination of giant goldenrod achenes and to determine: the influence of temperature and humidity on seed dormancy and germination,
\end{abstract}

Communicated by MJ Reigosa.

Anna Bochenek

anna.bochenek@uwm.edu.pl

Agnieszka Synowiec

a.stoklosa@ur.krakow.pl

Bożena Kondrat

bozena2306@interia.pl

Milena Szymczak

milena.szymczak@uwm.edu.pl

Lesław B. Lahuta

lahuta@uwm.edu.pl

Janusz Gołaszewski

janusz.golaszewski@uwm.edu.pl

1 Department of Plant Physiology, Genetics and Biotechnology, University of Warmia and Mazury, Oczapowskiego 1A, 10-719 Olsztyn, Poland

2 Depertament of Agrotechnology and Agricultural Ecology, University of Agriculture in Kraków, Al. Mickiewicza 21, 31-120- Kraków, Poland

3 Department of Plant Breeding and Seed Production, University of Warmia and Mazury, Pl. Lódzki 3, 10-724 Olsztyn, Poland the content of soluble carbohydrates in seeds and the sensitivity of seeds to selected phytohormones. Unlike native weed species of the same family, S. gigantea seeds did not display symptoms of innate dormancy, and high seed vigor was maintained after storage in a wide range of temperatures, in both dry and moist conditions. The physiological mechanisms behind those traits have not yet been fully explored, but they could be associated with the relatively high sucrose-to-hexose ratio in seeds and significant sensitivity to abscisic acid. More extensive research is required to explain the internal causes for the atypical behavior of goldenrod seeds during dry and moist storage, especially in the context of its invasiveness, because the species has a preference for sites located close to river banks.

Keywords Humidity · Phytohormone sensitivity · Plant invader - Seed dormancy - Solidago gigantea Ait. ·

Temperature

\section{Introduction}

Selected plant species are characterized by considerable invasiveness, which carries many risks. Such plants easily spread and colonize new habitats, becoming the dominant species in the flora (Mack et al. 2000), which leads to a rapid decrease in biodiversity, especially in relation to the native species. In Europe, the giant goldenrod (Solidago gigantea Ait.) and the Canadian goldenrod (S. canadensis L.) are among the five most expansive environmental weeds (Sheppard et al. 2006; Weber 2001), and they are the most dangerous plant-invaders of American origin.

The giant goldenrod was introduced to Europe in the eighteenth century as an ornamental plant (Weber and Schmid 1998; Weber and Jacobs 2005). This perennial 
herb reproduces by seeds or persistent, underground rhizomes. The species is insect-pollinated (Mellville and Morton 1982). The first records of giant goldenrod's presence in Poland date back to 1853, and the species has been spreading rapidly since 1940 (Tokarska-Guzik 2001, 2003). Presently, the giant goldenrod is noted mainly in ruderal sites, fallows and water-logged habitats such as ditches or river banks (Meyer and Schmid 1999a; Stokłosa et al. 2013). The species colonizes a given area in the form of single plants, patches or dense canopies. The giant goldenrod is much more prevalent in south-western and central Poland (Szymura and Szymura 2013; Kołaczkowska 2012), and it occurs far less frequently in the north-eastern part of the country (Korniak et al. 2012).

There are many reasons for the ecological success of invasive goldenrods in Europe, including their considerable ecological tolerance: both species colonize habitats characterized by diverse soil texture, $\mathrm{pH}$ or nutrient content (Szymura and Szymura 2013; Pużyńska et al. 2012). Goldenrod populations develop rapidly due to very high levels of competitiveness and their allelopathic effects (Abhilasha et al. 2008; Meyer and Hull-Sanders 2008; Yuan et al. 2012). Their rapid spread can also be attributed to the absence of herbivorous insects that are attracted to goldenrod canopies. According to Jacobs et al. (2004), goldenrods are rarely damaged by insects in Europe, unlike their native populations in America. The last, but not least, reason for the significant invasiveness of American goldenrods is their reproduction pattern. The giant goldenrod reproduces through viable, hair-equipped and wind-dispersed seeds (Weber and Jacobs 2005), and vegetatively through rhizomes, and it is the most dangerous plant-invader of American origin. It has been shown that goldenrod plants are capable of producing new shoots from rhizome fragments buried as deep as $20 \mathrm{~cm}$ below ground surface (Weber 2011). The introduced populations of giant goldenrod produce more shoots by clonal growth than native populations. This ability enhances growth in poor soils or dense stands (Güsewell et al. 2006).

In early stages of giant goldenrod invasion, nutrient allocation to developing rhizomes can increase the plant's overwintering success and contribute to further clonal spread in the habitat (Szymura and Szymura 2014). This strategy could substantially increase the density of ramets and, consequently, seed production (Jacobs et al. 2004). Seed production is a trait that enables goldenrods to easily colonize new habitats. A single ramet produces up to 19,000 achenes which are $1-1.8 \mathrm{~mm}$ long. A higher number of lighter seeds is produced in unsupportive environments to guarantee dispersal across long distances. Under favorable growth conditions, the produced achenes are larger, which facilitates the establishment of seedlings in areas with dense vegetation (Werner and Platt 1976).
In view of the above, a sound knowledge of the germination biology of goldenrods is required to control the spread of this invasive species. To date, there has been very little published research into the factors that affect the germination of invasive goldenrod seeds. Walck et al. (1997a, b) conducted a series of experiments comparing the germination biology of the widespread (and invasive in Europe) $S$. altissima and the endemic $S$. shortii. The authors demonstrated that light conditions and cold stratification significantly influenced the germination of Solidago seeds. They also found that the analyzed Solidago species exhibited an annual conditional dormancy/nondormancy cycle.

Seed dormancy and germination are the most important periods in a plant's early life. The processes that take place during dry storage of mature seeds discarded by the parent plant are referred to as after-ripening. After-ripening is determined by temperature and moisture content. Despite low water content, processes related to breaking or induction of dormancy can take place during seed storage. Storage of imbibed ripe seeds is known as stratification, and this treatment can also be applied to induce or break dormancy (Holdsworth et al. 2008; Weitbrecht et al. 2011). Temperature is a key environmental factor regulating dormancy and germination. During seed maturation, temperature influences innate dormancy, and when seeds become a part of the soil seed bank, temperature and moisture content are the key factors that regulate and synchronize the dormancy cycle across seasons (Kendall and Penfield 2012; Kundel et al. 2014; Nambara et al. 2010).

Seed dormancy is regulated by a set of phytohormones. The proportions in which those phytohormones occur, in particular the ratio of abscisic acid to gibberellins, change dynamically and influence the dormancy/germination ratio. According to many authors (Wu et al. 2000; Toorop et al. 2000; da Silva et al. 2004; Finch-Savage and LeubnerMetzger 2006), dormancy and germination are not determined by absolute hormone concentrations, but by the proportions in which those hormones occur, as well as by the sensitivity of seeds to those hormones. Seed resistance to stress, seed vigor and dormancy are also influenced by soluble carbohydrate levels (Hilhorst 1995). As seeds get older, the amount of soluble sugars decreases, which limits seed vitality, decreases germination ability and compromises the structural integrity of membranes (Bernal-Lugo and Leopold 1992; Obendorf and Gorecki 2012; Corbineau 2012).

The aim of this study was to analyze the effect of moist and dry storage conditions (stratification and after-ripening) on the physiological characteristics of $S$. gigantea achenes, such as dormancy, germination capacity and seed vigor. Attempts were also made to determine whether those unique physiological properties are responsible for the species' invasiveness. The research goal was achieved by 
analyzing the parameters of a hydrotime model, which is a highly popular method. In seeds, dormancy is regulated hormonally, therefore, attempts were made to analyze goldenrod seeds' sensitivity to abscisic acid and gibberellins. High germination capacity and seed vigor are correlated with significant resistance to environmental stress. The carbohydrate profile of seeds, an important taxonomic characteristic, was analyzed to validate the above observation. The following tasks were carried out to achieve the research objectives: (1) the influence of temperature and humidity on seed dormancy and germination was determined, (2) the content of soluble carbohydrates in seeds was measured, and (3) seed sensitivity to selected phytohormones was evaluated.

\section{Materials and methods}

Mature seed lots of S. gigantea were collected on fallow land, located near Vistula river in the vicinity of Cracow (SE Poland), on a moist but not flooded site.

\section{The effect of constant temperatures and humidity on seed germination and dormancy in a hydrotime model}

Seed lots of $S$. gigantea were packaged separately in envelopes of fine nylon mesh, immediately after collection. Nine envelopes with seeds were buried in wet light loam (18\% water content) in a tightly closed plastic pot and stored at 5, 12 or $19^{\circ} \mathrm{C}$ for 80 days. The seeds were stratified at lower temperatures. The remaining seed lots were packaged separately in paper bags and stored at 12 , 19 or $26{ }^{\circ} \mathrm{C}$ for 80 days. These seed lots were subjected to after-ripening at higher temperatures. Preliminary analyses were conducted after 150 days of storage, but significant changes in dormancy or germination of achenes were not observed after 80 days of storage. Before the experiment and after 7,20 and 80 days of storage, seeds from each temperature and experimental group were subjected to a germination test in $9 \mathrm{~cm}$ Petri dishes on filter paper moistened $(3.5 \mathrm{~mL})$ with water or polyethylene glycol (PEG 8000) solutions with reduced water potentials ( 0 , -0.3 and $-0.6 \mathrm{MPa}$, according to Michel 1983), in three replications of 50 seeds each $\left(30 / 20{ }^{\circ} \mathrm{C}, 16 / 8 \mathrm{~h}\right.$ light/dark), for 10 days. Water potentials were checked using a vapor pressure osmometer (Wescor model Vapro 5520) calibrated against $\mathrm{NaCl}$ standards. Before the test, seeds were immersed in $0.25 \%$ natamycin suspension for $1 \mathrm{~h}$ to eliminate pathogenic fungi from the surface. Germination was registered at $4,8,12,16$ or $24 \mathrm{~h}$ intervals, depending on germination rate. The dishes were placed in transparent plastic bags to prevent evaporation, and they were subsequently incubated in a low-temperature incubator (Heraeus BK 6160). Ungerminated seeds were transferred to fresh solutions at 48-h intervals to maintain constant $\psi$ in the dishes. Protrusion of the radicle was the criterion for germination. Ungerminated seeds were considered viable if firm when squeezed with forceps. Tetrazolium tests confirmed that firm embryos were viable, but soft ones were not. Seed germination time courses in water and osmotic solutions were analyzed according to the population-based hydrotime model and the computational procedure proposed by Bradford (1990, 1995) and Gołaszewski and Bochenek (2008). The hydrotime model defined by Gummerson (1986) has the following form:

$\theta_{H}=\left(\psi-\psi_{b}(g)\right) \cdot t_{g}$

$\mathrm{GR}_{g}=1 / t_{g}=\left(\psi-\psi_{b}(g)\right) / \theta_{H}$

where $\theta_{H}$ is the hydrotime constant in a seed population, $\psi$ is the water potential of a seed population, $\psi_{b}(g)$ is the water potential threshold of a specific germination fraction $g, t_{g}$ is the germination time of the corresponding fraction $g, \mathrm{GR}_{g}$ is the germination rate of a given seed fraction. This procedure was used to calculate hydrotime parameters $\theta_{H}$, $\psi_{b}(50)$ and $\sigma_{\psi_{b}}$ of the seed population. Germination timecourse curves for the seed population were developed by repeated probit regression according to the following equation:

$\operatorname{probit}_{(g)}=\left[\psi-\left(\theta_{H} / t_{g}\right)-\psi_{b}(50)\right] / \sigma_{\psi_{b}}$

The values of three hydrotime model parameters, $\theta_{H}$, $\psi_{b}(50)$ and $\sigma_{\psi_{b}}$, are useful indicators of changes in the physiological properties of the examined seed lot. The hydrotime constant $\theta_{H}$ is an indicator of the overall rate of germination. The lower the value of $\theta_{H}$, the higher the germination rate. This parameter can also be an indicator of seed aging. The value of $\psi_{b}(50)$ is an indicator of stress tolerance and general vigor, whereas $\sigma_{\psi_{b}}$ provides information about the uniformity of germination (Bradford 2002). The hydrotime model supports accurate predictions of the proportion of seeds which have entered dormancy. Dormancy level and external factors, such as temperature and water potential, simultaneously influence germination (Larsen et al. 2004; Bradford and Still 2004).

\section{Analysis of soluble carbohydrates}

The content of soluble carbohydrates was analyzed by high resolution gas chromatography on a ZEBRON ZB-1 capillary column (Phenomenex, USA), according to the method developed by Lahuta and Górecki (2011). Soluble carbohydrates were extracted from $40 \mathrm{mg}$ of seed meal with $800 \mu \mathrm{L}$ of ethanol-water mixture $\left(1: 1, \mathrm{v} / \mathrm{v}\right.$, at $90{ }^{\circ} \mathrm{C}$ for $30 \mathrm{~min}$ ) containing $100 \mu \mathrm{g}$ of xylitol (internal 
standard), which was centrifuged, deionized and evaporated in a speed vacuum rotary evaporator to dryness. Dry residues were derivatized with $200 \mu \mathrm{L}$ of the TMSI and pyridine mixture (Sigma, St. Louis, USA) at $70{ }^{\circ} \mathrm{C}$ for $45 \mathrm{~min}$. The content of soluble carbohydrates was calculated from the ratios of peak area for each known carbohydrate to peak area for internal standards. Carbohydrate standards were purchased from Sigma (USA). The quantities of soluble carbohydrates (in $\mu \mathrm{g} \mathrm{mg}^{-1}$ of dry weight, DW) were expressed as means for three replications $\pm \mathrm{SE}$. Data were processed by analysis of variance (ANOVA) and means were compared by Tukey's test $(P<0.05)$.

\section{The sensitivity of seeds to gibberellins and abscisic acid}

Germination tests were performed in $9 \mathrm{~cm}$ Petri dishes on filter paper moistened with $(3.5 \mathrm{~mL})$ distilled water or aqueous solutions of 100 and $1000 \mathrm{mM}$ gibberellic acid $4+7$ (Duchefa Biochemie, The Netherlands) or 10 and $100 \mu \mathrm{M}$ paclobutrazol (Duchefa Biochemie, The Netherlands), or 10 and $100 \mu \mathrm{M}$ abscisic acid (Olchemim, Czech Republic), or 10 and $100 \mu \mathrm{M}$ fluridone (Olchemim, Czech Republic), in three replications of 50 seeds each $\left(30 / 20{ }^{\circ} \mathrm{C}\right.$, $16 / 8 \mathrm{~h}$ light/dark) for 10 days. Fluridone solution was prepared by dissolving the substance completely in $0.5 \mathrm{~mL}$ of $95 \%$ ethanol $(\mathrm{v} / \mathrm{v})$ and adding $0.2 \mathrm{~mL}$ of Tween 20 (Sigma Aldrich, Germany) before combining with distilled water (Ober and Sharp 1994). Gibberellins, paclobutrazol and abscisic acid solutions were prepared by dissolving the substances completely in $0.5 \mathrm{ml}$ of $95 \%$ ethanol (v/v) and combining with distilled water. Preliminary analyses revealed that neither ethanol nor Tween 20 [at final concentrations of 0.05 and $0.02 \%(\mathrm{v} / \mathrm{v})$, respectively] had a discernible effect on seed germination. Data were processed by analysis of variance (ANOVA), and means were compared by Tukey's test $(P<0.05)$. Germination percentages were arcsine transformed to stabilize variances.

\section{Results}

Dry storage of seeds at 12,19 and $26^{\circ} \mathrm{C}$ had a minor influence on final germination (FG) and the parameters of the hydrotime model of $S$. gigantea achenes. Seeds germinated rapidly and with nearly $100 \%$ success regardless of temperature and storage time. The sensitivity of achenes to lower water potentials $(-0.3$ and $-0.6 \mathrm{MPa})$ did not change (Fig. 1). Only long-term storage at $19{ }^{\circ} \mathrm{C}$ decreased final germination percentage by around $9 \%$ due to the movement of $\Psi_{\mathrm{b}}$ distribution to less negative values (Fig. 1m, n). Insignificant changes in the values of FG and the parameters of the hydrotime model were reflected in
Fig. 1 Germination time courses of $S$. gigantea seeds after dry storage for $0,7,20$ and 80 days in 12,19 and $26^{\circ} \mathrm{C} . \mathbf{a}, \mathbf{c}, \mathbf{e}, \mathbf{g}, \mathbf{i}, \mathbf{k}, \mathbf{~ m}$, $\mathbf{0}, \mathbf{q}, \mathbf{s}$ Germination time courses of seeds at 0 (circles), -0.3 (triangles) and -0.6 (rhombuses) MPa. b, d, f, h, j, l, n, p, r, $\mathbf{t}$ Normal distribution showing the relative frequencies of $\Psi_{b}$ values of seeds

low values of the coefficients of variation (CV). Depending on storage temperature, the values of $\mathrm{CV}$ reached 0.4-5, $10-17,7-14$ and $7-17$ for FG, $\Psi_{\mathrm{b}}(50), \sigma_{\Psi_{b}}$ and $\theta_{H}$ in drystored seeds, respectively (Table 1).

Moist storage of seeds resulted in rapid and high (approximately $100 \%$ ) germination which increased with the period of storage at $5{ }^{\circ} \mathrm{C}$ and $12{ }^{\circ} \mathrm{C}$. The distribution of $\Psi_{b}$ values moved to the left, $\theta_{H}$ values decreased, and minor fluctuations were noted in $\sigma_{\Psi b}$ values (Fig. 2; Table 2). At $19{ }^{\circ} \mathrm{C}$, final germination was also rapid and marked by nearly $100 \%$ success. The values of $\Psi_{b}(50)$ increased after short-term storage and decreased after long-term storage. The hydrotime constant decreased after both short-term and long-term storage (Table 2), whereas the distribution of base water potential in the seed population did not change. Only minor differences were observed in final germination values at different temperatures (CV 1). Depending on storage temperature, the values of $\mathrm{CV}$ reached 11-19, 5-14 and 20-27 for $\Psi_{b}(50), \sigma_{\Psi b}$ and $\theta_{H}$ in moist-stored seeds, respectively (Table 2), which suggests that changes in the mean base water potential and hydrotime constant were somewhat greater in moist-stored seeds than in dry-stored seeds.

The coefficient of determination $R^{2}$ for all treatments ranged from 0.705 to 0.934 , which indicates good fit of the model to experimental results (Tables 1, 2).

A total of 13 soluble carbohydrates and their derivatives were identified in $S$. gigantea seeds. The main sugar was sucrose whose content was determined at $6.49 \mathrm{mg} \mathrm{g}^{-1}$ DW. The remaining soluble carbohydrates were present in significantly smaller quantities. The content of raffinose, the second most abundant sugar, reached $4.25 \mathrm{mg} \mathrm{g}^{-1}$ DW. Stachyose, another raffinose family oligosaccharide (RFO), was found in trace amounts. The analyzed seeds also contained polyhydric alcohols mannitol and arabitol (2.07 and $0.74 \mathrm{mg} \mathrm{g}^{-1} \mathrm{DW}$, respectively). The content of trehalose, a non-reducing disaccharide, was determined at $0.9 \mathrm{mg} \mathrm{g}^{-1} \mathrm{DW}$. The presence of two unidentified compounds was observed. Their positions in the chromatogram suggest that unknown compound 1 (UNK-1) was a trisaccharide (the content of UNK-1 was determined relative to the content of raffinose, its nearest neighbor in the chromatogram), and unknown compound 2 (UNK-2) was a tetrasaccharide (the content of UNK-2 was determined relative to the content of stachyose) $\left(0.69\right.$ and $1.66 \mathrm{mg} \mathrm{g}^{-1}$ DW, respectively). Trace amounts of monosaccharides- 

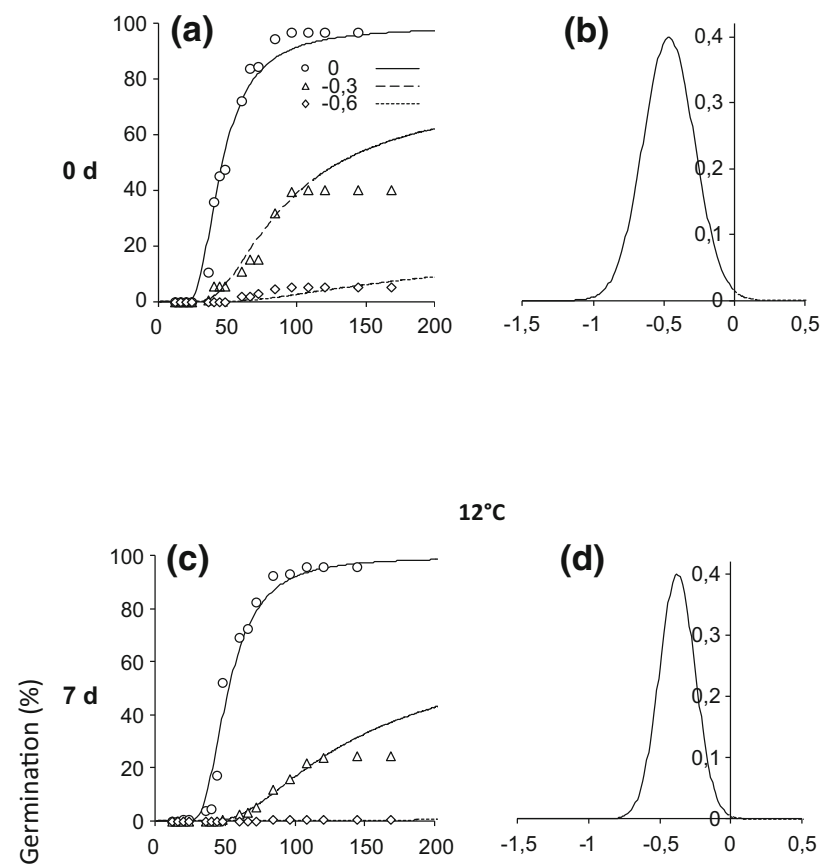

$12^{\circ} \mathrm{C}$
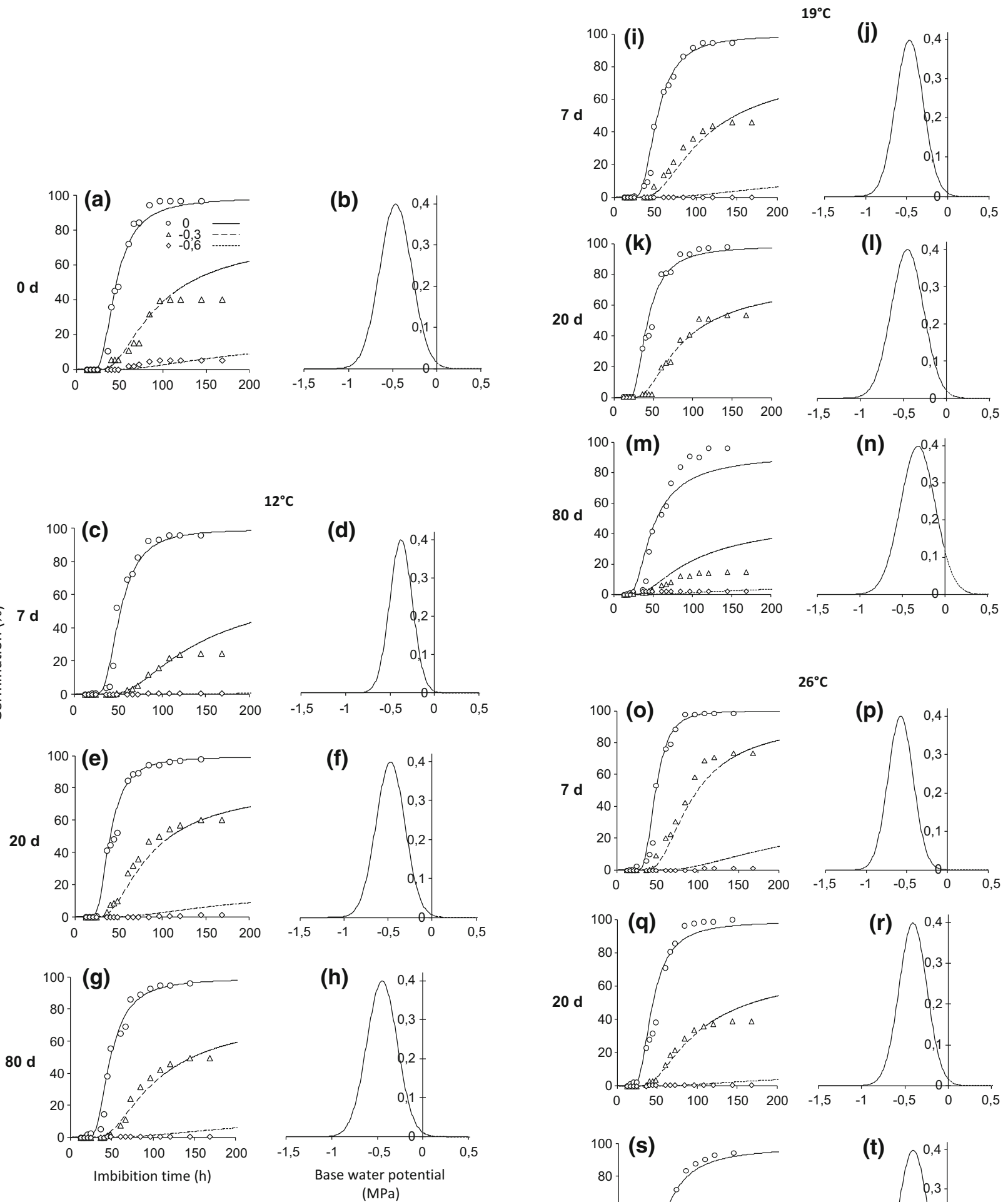

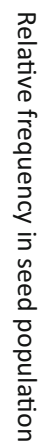

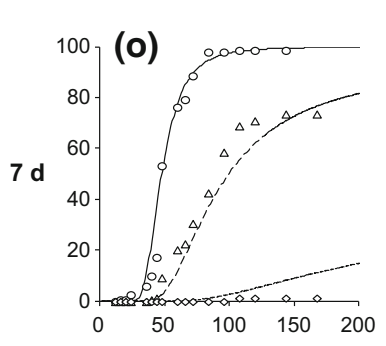

$26^{\circ} \mathrm{C}$
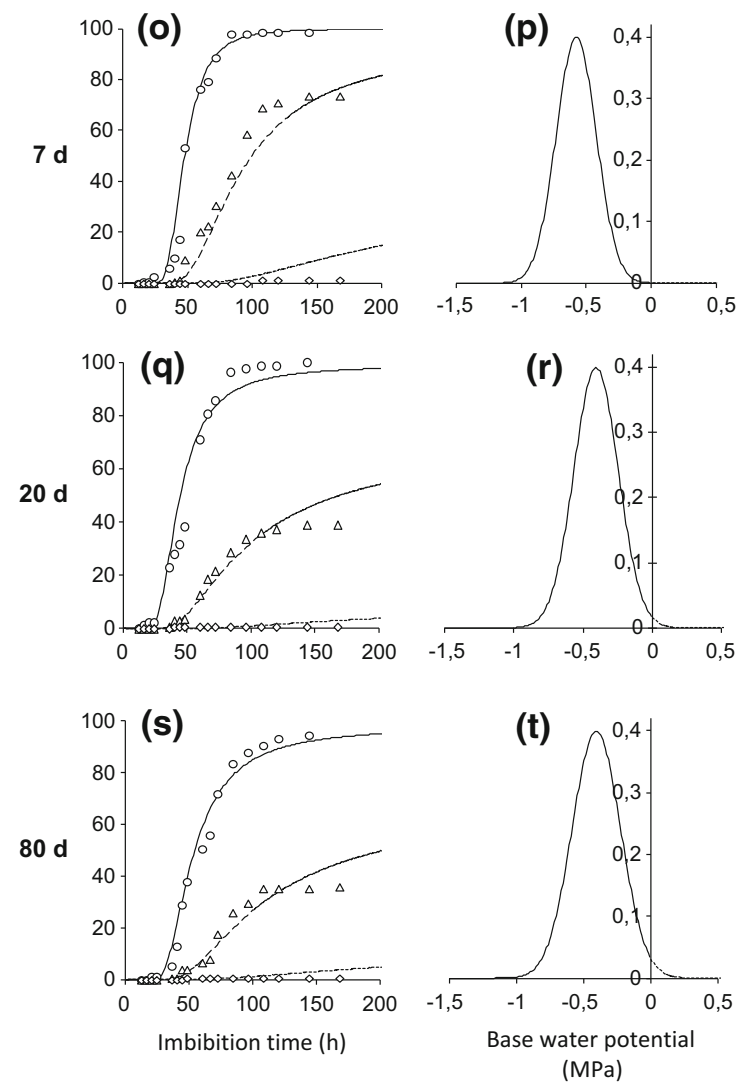
Table 1 Parameters of the hydrotime model and indices of goodness of fit characterizing germination of $S$. gigantea seeds after dry storage for $0,7,20$ and 80 days in 12,19 and $26^{\circ} \mathrm{C}$

\begin{tabular}{lllllll}
\hline$T\left({ }^{\circ} \mathrm{C}\right)$ & $t$ (days) & FG $(\%)$ & $\Psi_{b}(50)(\mathrm{MPa})$ & $\sigma_{\Psi_{b}}(\mathrm{MPa})$ & $\theta_{H}(\mathrm{MPa} \mathrm{h})$ & $R^{2}$ \\
\hline Fresh seeds & 0 & 98.5 & -0.47 & 0.18 & 21.6 & 0.848 \\
12 & 7 & 99.3 & -0.38 & 0.13 & 19.9 & 0.923 \\
12 & 20 & 99.4 & -0.47 & 0.16 & 19 & 0.825 \\
12 & 80 & 98.8 & -0.45 & 0.17 & 21.8 & 0.867 \\
& Mean (CV) & $99(0.4)$ & $-0.44(10)$ & $0.16(14)$ & $20.6(7)$ & - \\
19 & 7 & 98.9 & -0.47 & 0.17 & 24.8 & 0.873 \\
19 & 20 & 98.2 & -0.46 & 0.19 & 19.6 & 0.705 \\
19 & 80 & 89.9 & -0.32 & 0.2 & 17.3 & 0.906 \\
& Mean (CV) & $96.4(5)$ & $-0.43(17)$ & $0.19(7)$ & $20.8(15)$ & - \\
26 & 7 & 99.9 & -0.58 & 0.16 & 27.5 & 0.877 \\
26 & 20 & 98.5 & -0.41 & 0.16 & 18.1 & 0.876 \\
26 & 80 & 96.8 & -0.41 & 0.18 & 22.2 & 0.878 \\
& Mean (CV) & $98.4(1)$ & $-0.47(17)$ & $0.17(7)$ & $22.3(17)$ & - \\
\hline
\end{tabular}

$T$ storage temperature, $t$ storage time, $F G$ final germination in water, $\Psi_{b}(50)$ mean base water potential, $\sigma_{\Psi b}$ standard deviation of base water potential, $\theta_{H}$ hydrotime constant, $C V$ coefficient of variation expressed as a percentage of the mean, $R^{2}$ coefficient of determination of probit regressions glucose and fructose, cyclitols-D-chiro-inositol and myoinositol, and a mono-galactosyl cyclitol-galactinol, were also determined (Fig. 3). Sucrose and raffinose were rapidly degraded during the first 3 days of seed germination, which coincided with an increase in the levels of monosaccharides (glucose and fructose), mannitol, myoinositol and trehalose (data not shown).

Solidago gigantea achenes from the control group germinated in $98 \%$, and their germination rates were not affected by differences in the concentrations of gibberellins $4+7$. Paclobutrazol visibly inhibited germination-by up to $75 \%$ at a concentration of $10 \mu \mathrm{M}$ and by up to $97 \%$ at a concentration of $100 \mu \mathrm{M} \%$. Abscisic acid also significantly inhibited germination-by up to $56 \%$ at a concentration of $10 \mu \mathrm{M}$ and by up to $88 \%$ at a concentration of $100 \mu \mathrm{M}$. Incubation in a $10 \mu \mathrm{M}$ fluridone solution did not significantly inhibit germination relative to the control treatment. Fluridone at a concentration of $100 \mu \mathrm{M}$ significantly decreased germination, but the observed reduction was less pronounced than that caused by paclobutrazol and abscisic acid (Fig. 4).

\section{Discussion}

Solidago gigantea produces huge amounts of small and light seeds equipped with dispersal mechanisms (Weber and Jacobs 2005), which could suggest that generative reproduction is very important for both regeneration and propagation in the species.

Solidago gigantea seeds did not display symptoms of innate dormancy. In the analyzed species, high seed vigor was maintained after storage in a wide range of temperatures, in both dry and moist conditions, which is an important physiological trait of this invasive weed for the formation of a viable seed bank.

Stratification and after-ripening had only a minor effect on germination rate and final germination percentage. Hydrotime model parameters were not significantly affected either. However, the seeds of native weed species of the family Asteraceae were clearly sensitive to the above treatments (Bochenek et al. 2009, 2010). In the seeds of Matricaria maritima subsp. indora (scentless mayweed), innate dormancy was broken by cold stratification (Bochenek et al. 2010). The seeds of Cirsium arvense (creeping thistle) broke primary dormancy under the influence of moderate thermal stratification, whereas dry storage induced secondary dormancy (Bochenek et al. 2009). Similar responses to stratification and after-ripening were observed in the seeds of Taraxacum officinale (common dandelion) and Centaurea cyanus (cornflower), but in this case, changes in dormancy had a different physiological background because hydrotime model parameters changed in a different manner (Bochenek 2010). In comparison with the seeds of $C$. cyanus, $T$. officinale or M. maritima subsp. inodora, goldenrod seeds were highly resistant to environmental stressors. Features such as very high germination capacity, which was preserved regardless of storage conditions, provide seeds with competitive advantage over species that remain dormant for a large part of the year and require specific conditions to break dormancy. Seeds that do not lose viability germinate rapidly when supportive environmental conditions arise. Such conditions may appear both in the established vegetation and in new habitats invaded by Solidago, as long as openings in the existing vegetation support seedling emergence and 

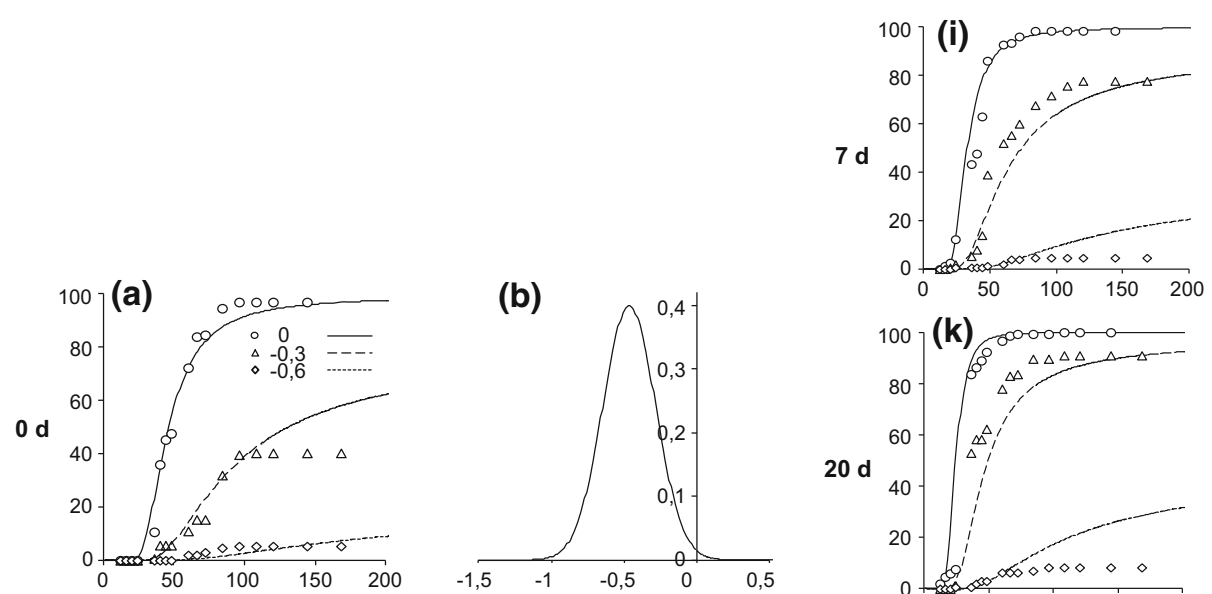

$12^{\circ} \mathrm{C}$
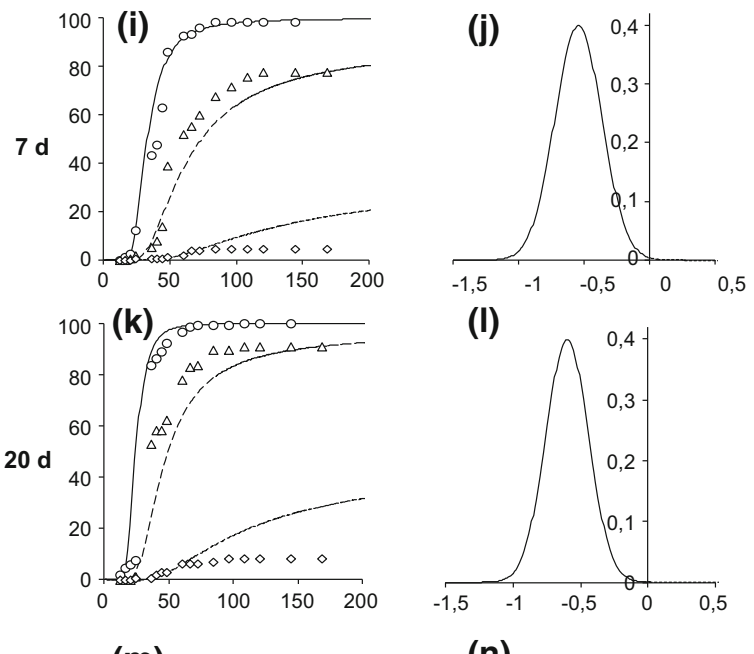

$5^{\circ} \mathrm{C}$
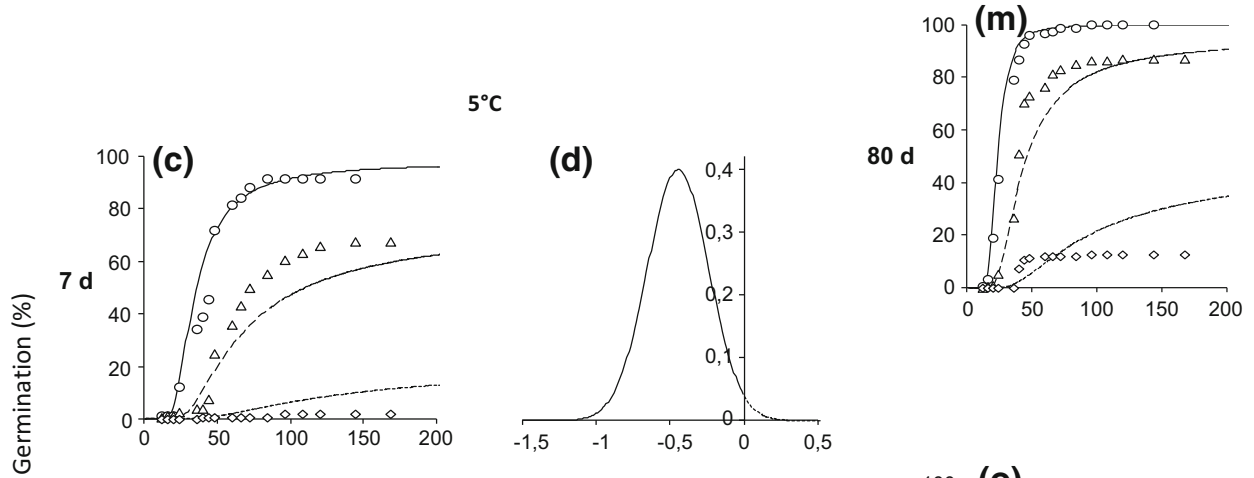

(n)

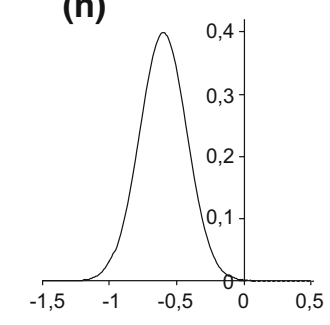

(f)
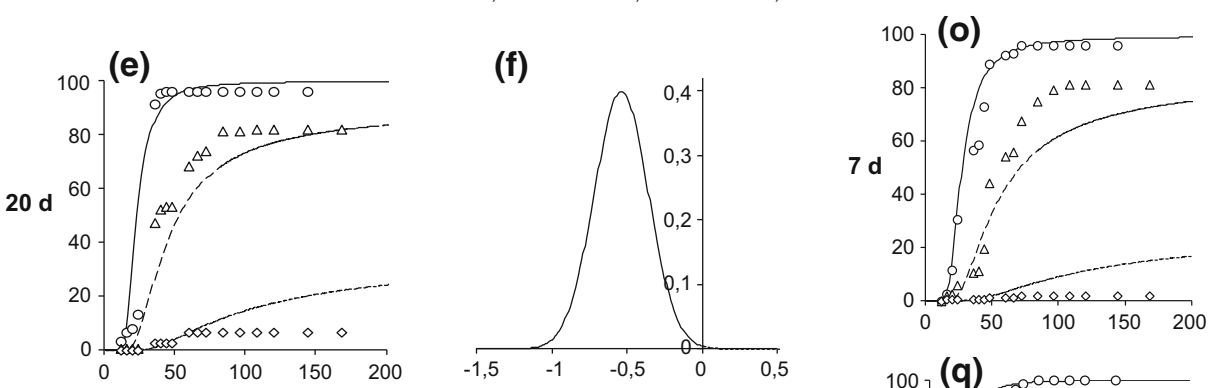

$19^{\circ} \mathrm{C}$
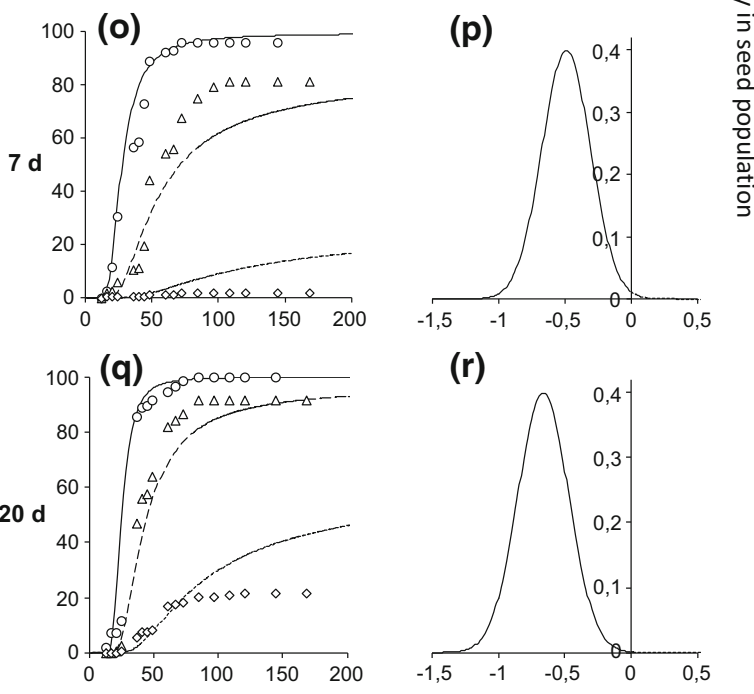

(r)
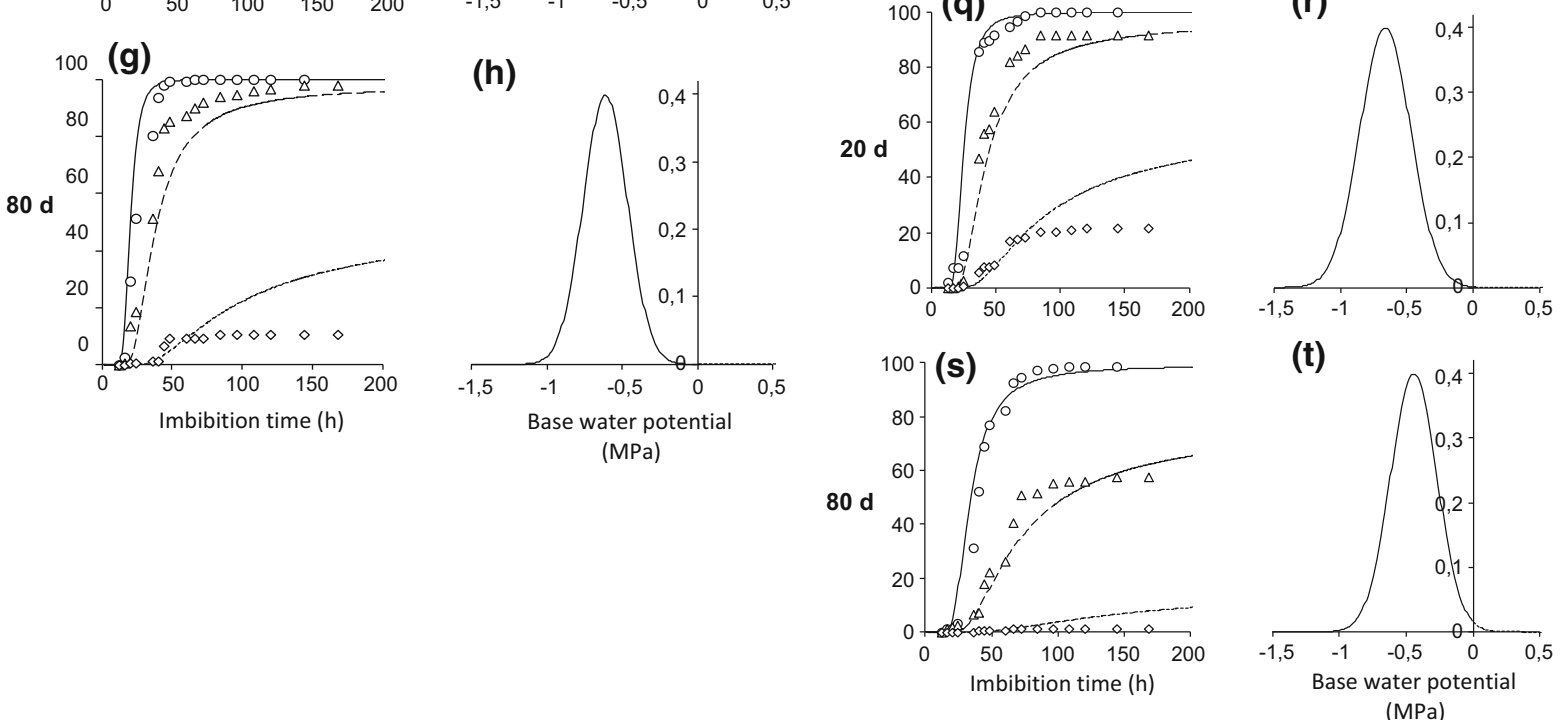

Fig. 2 Germination time courses of S. gigantea seeds after burial for 0, 7, 20 and 80 days in 5, 12 and $19{ }^{\circ} \mathrm{C}$. The symbols, lines and letters are identical to those in Fig. 1 
Table 2 Parameters of the hydrotime model and indices of goodness of fit characterizing germination of $S$. gigantea seeds after burial for $0,7,20$ and 80 days in 5,12 and $19^{\circ} \mathrm{C}$

\begin{tabular}{lllllll}
\hline$T\left({ }^{\circ} \mathrm{C}\right)$ & $t$ (days) & FG $(\%)$ & $\Psi_{b}(50)(\mathrm{MPa})$ & $\sigma_{\Psi b}(\mathrm{MPa})$ & $\theta_{H}(\mathrm{MPa} \mathrm{h})$ & $R^{2}$ \\
\hline Fresh seeds & 0 & 98.5 & -0.47 & 0.18 & $21.60,945$ & 0.848 \\
5 & 7 & 97.1 & -0.45 & 0.21 & 16.2 & 0.789 \\
5 & 20 & 99.6 & -0.54 & 0.18 & 12.7 & 0.773 \\
5 & 80 & 100.0 & -0.61 & 0.15 & 12.4 & 0.831 \\
& Mean $(\mathrm{CV})$ & $98.8(1)$ & $-0.52(14)$ & $0.18(14)$ & $15.7(27)$ & - \\
12 & 7 & 99.4 & -0.54 & 0.18 & 18 & 0.802 \\
12 & 20 & 100.0 & -0.6 & 0.16 & 14.7 & 0.828 \\
12 & 80 & 99.9 & -0.6 & 0.18 & 14 & 0.778 \\
& Mean (CV) & $99.4(1)$ & $-0.55(11)$ & $0.18(6)$ & $17.1(20)$ & - \\
19 & 7 & 98.9 & -0.49 & 0.18 & 13.7 & 0.809 \\
19 & 20 & 99.9 & -0.66 & 0.19 & 16.3 & 0.79 \\
19 & 80 & 98.28 & -0.44 & 0.17 & 15.3 & 0.792 \\
& Mean (CV) & $98.9(1)$ & $-0.52(19)$ & $0.18(5)$ & $16.7(21)$ & - \\
\hline
\end{tabular}

The symbols as Table 1

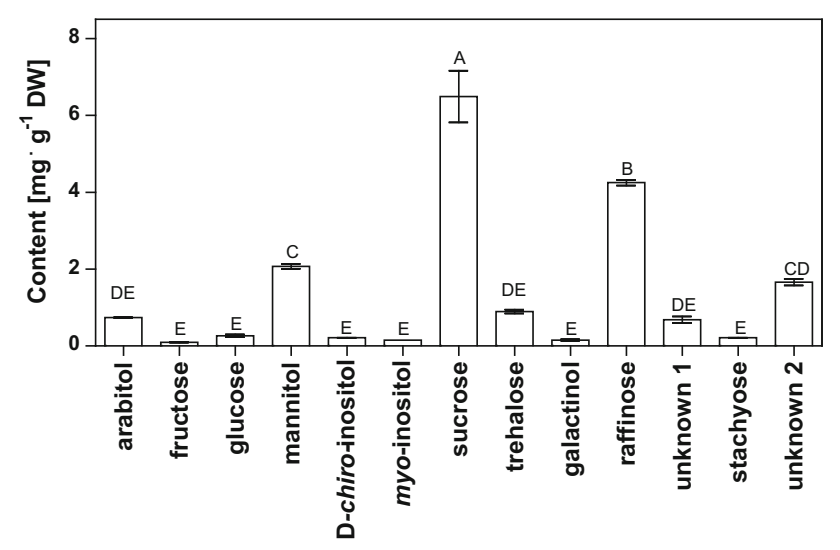

Fig. 3 The content of soluble sugars, cyclitols and galactosyl cyclitols in S. gigantea seeds. Data are presented as the means of three replications $\pm \mathrm{SE}$. Bars with the same letters are not significantly different $(P<0.05)$ after Tukey's test (ANOVA) establishment (Meyer and Schmid 1999b; Goldberg and Werner 1983). According to these authors, many seedlings are lost after dispersal, but those losses are not significant for the population which is characterized by extremely high fecundity and very light seeds. Resistance to changes in seed viability under the influence of various environmental factors may be attributed to different internal causes.

This study aimed to determine the biochemical or physiological traits which make goldenrod seeds more resistant than the seeds of other native species of the family Asteraceae. A knowledge of such traits could be helpful in developing new methods for controlling and minimizing damages caused by weed invasions. According to Pyšek and Richardson (2007), invasive organisms are characterized by unique traits which enable them to successfully colonize new habitats, such as morphological and physiological traits, reproductive parameters or specific responses

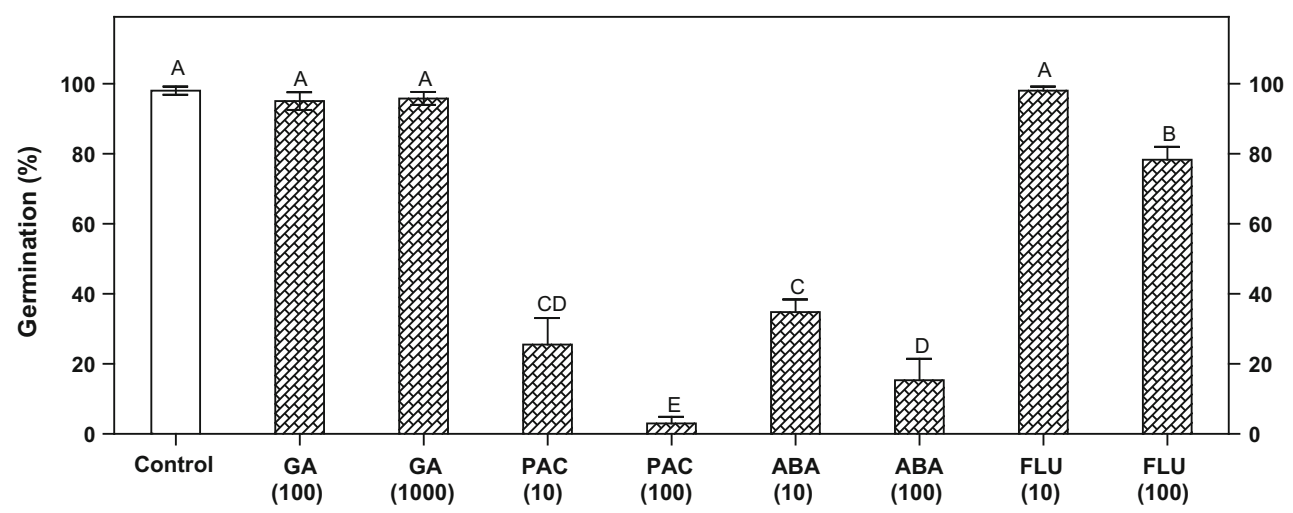

Fig. 4 Germination of $S$. gigantea seeds in solutions of phytohormones and inhibitors of their synthesis. $G A$ gibberellin $4+7, P A C$ paclobutrazol, $A B A$ abscisic acid, FLU fluridone. The numbers by the names of chemicals indicate $\mu \mathrm{M}$ concentration. Data are presented as the means of three replications \pm SE. Bars with the same letters are not significantly different $(P<0.05)$ after Tukey's test (ANOVA) 
to environmental factors. Those traits may be difficult to identify (Alpert et al. 2000), but they could explain the mechanisms of invasiveness. According to Pyšek and Richardson (2007), traits such as high germination capacity and low dormancy level contribute to invasiveness.

Seed resistance to abiotic stresses could be linked with the content of soluble carbohydrates. According to Alpert et al. (2000), invasiveness is related to resistance to environmental stressors. In plants, the mechanisms responsible for stress tolerance are regulated by hormones, and they are determined by the levels of stress hormones and sensitivity to those hormones.

The authors assumed that in the analyzed seeds, resistance to abiotic stresses could be attributed to their unique content of soluble carbohydrates. Goldenrod seeds contain disaccharides (sucrose and trehalose) and raffinose (RFO) which, next to fructans, are the basic soluble sugars responsible for plant responses to stress. Those carbohydrates are osmoprotectants which stabilize cell membranes during desiccation stress (Keunen et al. 2013). Disaccharides, galactinol, RFOs and sugar alcohols (arabitol and mannitol) can also scavenge free radicals in plants (Angelovici et al. 2010). Cyclitols and ether derivatives of cyclitols can also play important roles in resistance to abiotic stresses (Obendorf and Gorecki 2012). In lowtemperature acclimation, soluble carbohydrates participate in osmotic adjustment and cryoprotection of cellular structures (Travert et al. 1997). It was found, however, that the composition of soluble carbohydrates in S. gigantea Aiton seeds is comparable to that of other species of the family Asteraceae and other plant families (Pennycooke et al. 2003; Bochenek 2010; Obendorf et al. 2013, own unpublished data), although in the family Asteraceae, the concentrations of soluble sugars were determined only in the seeds of several species (Bochenek 2010; Bochenek unpublished data). In the analyzed seeds, the high sucroseto-hexose ratio could switch the specific sucrose signal to the induction of genes encoding the synthesis of secondary metabolites involved in defense responses (Kwon et al. 2011). Sucrose, the most abundant disaccharide in $S$. gigantea seeds, is presently regarded as the prime candidate for a signal molecule in the innate immunity of plants (Gómez-Arisa et al. 2007). An effective stress response is probably possible due to coordinated interactions between hormone and sugar signaling pathways. Cross-talk was observed in sugar and plant hormonal signaling networks to modulate processes such as embryo development and seed germination (Eveland and Jacson 2012). The above applies particularly to abscisic acid, a hormone which is responsible for the induction and maintenance of dormancy as well as the stress resistance of plants. For this reason, the observed high resistance of $S$. gigantea seeds before dormancy could be attributed to their unique sensitivity to the major hormones regulating seed dormancy and germination. It has been demonstrated that the phytohormonal balance between abscisic acid and gibberellins integrates external cues for inducing or maintaining dormancy (abscisic acid) and for breaking dormancy or inducing germination (gibberellins) (Arc et al. 2013). Dormant seeds treated with fluridone, an abscisic acid synthesis inhibitor, broke dormancy, which indicates that de novo biosynthesis of abscisic acid is required to maintain dormancy in imbibed seeds (Hu et al. 2012). Seed treatment with paclobutrazol, a gibberellins synthesis inhibitor, inhibited seed germination, which suggests that continuous synthesis of gibberellins is required during imbibition ( $\mathrm{Hu}$ et al. 2012). The abscisic acid/gibberellins equilibrium theory is commonly used to explain the mechanisms of dormancy and germination regulation (Nambara et al. 2010). The theory has been confirmed by molecular analyses which revealed that regulation of sensitivity to abscisic acid runs contrary to the control of sensitivity to gibberellins (Yamaguchi 2008). The cross-talk between abscisic acid and gibberellin signaling pathways can involve several factors, including FUS3 transcription factor or DELLA proteins (Nambara et al. 2010). The processes regulating seed dormancy during stratification and after-ripening are mostly related to changes in sensitivity to abscisic acid and gibberellins, but the concentrations of those hormones also change in seeds during those processes (Linkies and Leubner-Metzger 2012). Paclobutrazol significantly impaired the germination of goldenrod achenes, which suggests that gibberellins were synthesized de novo during imbibition, similarly to the achenes of $T$. officinale, a common native weed of the family Asteraceae, as well as other species, such as Leymus chinensis (Hu et al. 2012). Similarly to L. chinensis, but unlike $T$. officinale, the seeds of $S$. gigantea were also highly sensitive to abscisic acid (Bochenek 2010), and this trait could be related to stress resistance. The fact that $S$. gigantea did not enter dormancy during stratification or after-ripening could suggest that abscisic acid synthesis was not induced under those conditions or that seed sensitivity to this hormone was reduced.

In conclusion, it appears that long-term maintenance of seed viability and vigor, the absence of dormancy and resistance to environmental stressors are traits which, in addition to the previously investigated features, could be responsible for the invasiveness of S. gigantea transferred by seeds. The physiological mechanisms behind those traits have not yet been fully explored, but they could be associated with the relatively high sucrose-to-hexose ratio in seeds and significant sensitivity to ABA. More extensive research is required to explain the internal causes for the atypical behavior of goldenrod seeds during dry and moist storage, especially in the context of its invasiveness, because the species has a preference for sites located close to river banks. 
Author contribution statement Anna Bochenek, the idea of the paper, seed germination experiment, materials and methods, results and discussion writing, finalisation of publication. Agnieszka Synowiec, the idea of the paper, introduction writing, seed germination experiment. Bożena Kondrat, introduction writing, phytohormone experiment, soluble carbohydrates experiment. Milena Szymczak, figures, statistics, phytohormone experiment, soluble carbohydrates experiment. Lesław B. Lahuta, soluble carbohydrates experiment. Janusz Gołaszewski, hydrotime modeling, statistics.

Open Access This article is distributed under the terms of the Creative Commons Attribution 4.0 International License (http://crea tivecommons.org/licenses/by/4.0/), which permits unrestricted use, distribution, and reproduction in any medium, provided you give appropriate credit to the original author(s) and the source, provide a link to the Creative Commons license, and indicate if changes were made.

\section{References}

Abhilasha D, Quintana N, Vivanco J, Joshi J (2008) Do allelopathic compounds in invasive Solidago canadensis restrain the native European flora? J Ecol 96:993-1001

Alpert P, Bone E, Holzapfel C (2000) Invasiveness, invisibility and the role of environmental stress in the spread of non-native plants. Perspect Plant Ecol 3:52-66

Angelovici R, Galili G, Fernie AR, Fait A (2010) Seed desiccation: a bridge between maturation and germination. Trends Plant Sci 15:211-218

Arc E, Sechet J, Corbineau F, Rajjou L, Marion-Poll A (2013) ABA crosstalk with ethylene and nitric oxide in seed dormancy and germination. Front Plant Sci. doi:10.3389/fpls.2013.00063

Bernal-Lugo I, Leopold AC (1992) Changes in soluble carbohydrates during seed storage. Plant Physiol 98:1207-1210

Bochenek A (2010) Ecophysiological conditions of seed dormancy of weeds from Asteraceae family. Dissertation, University of Warmia and Mazury in Olsztyn

Bochenek A, Gołaszewski J, Piotrowicz-Cieślak AI, Górecki RJ (2009) The effects of temperature on the dormancy and germination of Cirsium arvense seeds. Acta Soc Bot Pol 78:105-114

Bochenek A, Gołaszewski J, Giełwanowska I (2010) A hydrotime model analysis of Matricaria maritima subsp. inodora seed dormancy. Plant Spec Biol 25:136-148

Bradford KJ (1990) A water relation analysis of seed germination rates. Plant Physiol 94:840-849

Bradford KJ (1995) Water relation in seed germination. In: Kigel J, Galili G (eds) Seed development and germination. Marcel Dekker, New York, pp 351-396

Bradford KJ (2002) Applications of hydrothermal time to quantifying and modeling seed germination and dormancy. Weed Sci 50:248-260

Bradford KJ, Still DW (2004) Applications of hydrotime analysis in seed testing. Seed Technol 26:75-85

Corbineau F (2012) Markers of seed quality: from present to future. Seed Sci Res 22:61-68

da Silva EAA, Toorop PE, van Aelst AC, Hilhorst HWM (2004) Abscisic Acid controls embryo growth potential and endosperm cap weakening during coffee (Coffea arabica cv. Rubi) seed germination. Planta 220:251-261

Eveland AL, Jacson DP (2012) Sugars, signaling, and plant development. J Exp Bot 63:3367-3377

Finch-Savage WE, Leubner-Metzger G (2006) Seed dormancy and the control of germination. New Phytol 171:501-523

Gołaszewski J, Bochenek A (2008) A computational procedure for hydrotime concept of seed germination. Biometr Let 45:55-67

Goldberg DE, Werner PA (1983) The effects of size of opening in vegetation and litter cover on seedling establishment of goldenrods (Solidago spp.). Oecol 60(2):149-155

Gómez-Arisa J, Campo S, Rufat M, Estopà M, Messeguer J, San Secundo B, Coca M (2007) Sucrose-mediated priming of plant defense responses and broad-spectrum disease resistance by overexpression of the maize pathogenesis-related PRms proteins in rice plants. Mol Plant Microbe Interact 20:832-842

Gummerson RJ (1986) The effect of constant temperatures and osmotic potential on the germination of sugar beet. J Exp Bot 37:729-741

Güsewell S, Jacobs G, Weber E (2006) Native and introduced populations of Solidago gigantea differ in shoot production but not in leaf traits or litter decomposition. Funct Ecol 20:575-584

Hilhorst HWM (1995) A critical update on seed dormancy. I. Primary dormancy. Seed Sci Res 5:61-73

Holdsworth MJ, Bentsink L, Soppe WJJ (2008) Molecular networks regulating Arabidopsis seed maturation, afterripening, dormancy and germination. New Phytol 178:1-21

Hu WX, Huang XH, Wang YR (2012) Hormonal and temperature regulation of seed dormancy and germination in Leymus chinenesis. Plant Growth Regul 67:199-207

Jacobs G, Weber E, Edwards PJ (2004) Introduced plants of invasive Solidago gigantea (Asteraceae) are larger and grow denser than conspecifics in the native range. Divers Distrib 10:11-19

Kendall S, Penfield S (2012) Maternal and zygotic temperature signaling in the control of seed dormancy and germination. Seed Sci Res 22:S23-S29

Keunen E, Peshev D, Vangronsveld J, van den Ende W, Cuypers A (2013) Plant sugars are crucial players in the oxidative challenge during abiotic stress: extending the traditional concept. Plant Cell Environ 36:1242-1255

Kołaczkowska E (2012) Siedliskowo-ekologiczne wzorce występowania obcych inwazyjnych gatunków roślin w dolinach małych rzek wschodniego Mazowsza. Wybrane aspekty. Studia i Materiały Centrum Edukacji Przyrodniczo-Leśnej, 14(4 [33])

Korniak T, Cz Hołdyński, Wąsowicz K, Święczkowska J (2012) American species of the genus Solidago in north-eastern Poland. Zesz Nauk UP Wroc Rol C 584:81-88

Kundel D, van Kleunen M, Dawson W (2014) Invasion by Solidago species has limited impacts on soil seed bank communities. Basic Appl Ecol 15:573-580

Kwon YE, Oh JE, Noh HN, Hong SW, Bhoo SH, Lee HJ (2011) The ethylene signaling pathway has a negative impact on sucroseinduced anthocyanin accumulation in Arabidopsis. J Plant Res 124:193-200

Lahuta LB, Górecki RJ (2011) Raffinose in seedlings of winter vetch (Vicia villosa Roth.) under osmotic stress and followed by recovery. Acta Physiol Plant 33:725-733

Larsen SU, Bailly C, Côme D, Corbineau F (2004) Use of the hydrothermal time model to analyse interacting effects of water and temperature on germination of three grass species. Seed Sci Res 14:35-50

Linkies A, Leubner-Metzger G (2012) Beyond gibberellins and abscisic acid: how ethylene and jasmonates control seed germination. Plant Cell Rep 31:253-270 
Mack RS, Simberloff D, Lonsdale WM, Evans H, Clout M, Bazzaz FA (2000) Biotic invasions: causes, epidemiology, global consequences, and control. Ecol Appl 10:689-710

Mellville MR, Morton JK (1982) A biosystematic study of the Solidago canadensis (Compositae) complex. I. The Ontario populations. Cant J Bot 60:976-997

Meyer GA, Hull-Sanders HM (2008) Altered patterns of growth, physiology and reproduction in invasive genotypes of Solidago gigantea (Asteraceae). Biol Invasions 10:303-3013

Meyer AH, Schmid B (1999a) Experimental demography of the oldfield perennial Solidago altissima: the dynamics of the shoot population. J Ecol 87:17-27

Meyer AH, Schmid B (1999b) Seed dynamics and seedling establishment in the invading perennial Solidago altissima under different experimental treatments. J Ecol 87:28-41

Michel BE (1983) Evaluation of the water potentials of solutions of the polyethylene glycol 8000 both in the absence and presence other solutes. Plant Physiol 72:66-70

Nambara E, Okamoto M, Tatematsu K, Yano R, Seo M, Kamiya Y (2010) Abscisic acid and the control of seed dormancy and germination. Seed Sci Res 20:55-67

Obendorf RL, Gorecki R (2012) Soluble carbohydrates in legume seeds. Seed Sci Res 22:219-242

Obendorf RL, Sensenig EM, Byrt EM, Owczarczyk AB, Ohashi M, Schnebly SR (2013) Cyclitol galactoides in low-raffinose, lowstachyose soybean embryos after feeding D-chiro-inositol, myoinositol or D-pinitol. Seed Sci Res 23:111-122

Ober ES, Sharp ES (1994) Proline accumulation in maize (Zea mais L.) primary roots at low water potentials. Physiol Plant 105:981-987

Pennycooke JC, Jones ML, Stushnoff (2003) Down-regulating $\alpha$ galactosidase enhances freezing tolerance in transgenic petunia. Plant Physiol 133:901-909

Pużyńska K, Stokłosa A, Stupnicka-Rodzynkiewicz E (2012) The impact of ecological conditions on Solidago sp. occurrence. Zesz Nauk UP Wroc Rol C 584:89-98

Pyšek P, Richardson M (2007) Traits associated with invasiveness in alient plants: where do we stand? Biol Invasions 193:97-125

Sheppard AW, Show RH, Sforza R (2006) Top 20 environmental weeds for classical biological control in Europe: a review of opportunities, regulations and other barriers to adoption. Weed Res 46:93-117

Stokłosa A, Puła J, Kacorzyk P, Ciężarek M (2013) Studies on location and calorific value of invasive species of the genus Solidago in the Pogórze Wiśnickie foothill. Proceedings of the International Scientific Conference "Bioenergy and other renewable energy technologies and systems", p 22

Szymura M, Szymura TH (2013) Soil preferences and morphological diversity of goldenrods (Solidago L.) from south-western Poland. Acta Soc Bot Pol 82:107-115

Szymura M, Szymura TH (2014) Growth, phenology, and biomass allocation of alien Solidago species in central Europe. Plant Spec Biol. doi:10.1111/1442-1984.12059
Tokarska-Guzik B (2001) The history of studies of invasive alien plants in Poland. In: Brundu G, Brock J, Camarda L, Child L, Wade M (eds) Plant invasions: species ecology and ecosystem management. Backhuys Publishers, Leiden, pp 245-254

Tokarska-Guzik B (2003) The expansion of some alien plant species (neophytes) in Poland. In: Child LE, Brock JH, Brundu G, Prach K, Pyšek P, Wade PM, Wiliamson M (eds) Plant invasions: ecological treats and management solutions. Backhuys Publishers, Leiden, pp 147-167

Toorop PE, van Aelst AC, Hilhorst HWM (2000) The second step of the biphasic endosperm cap weakening that mediates tomato (Lycopersicon esculentum) seed germination is under control of ABA. J Exp Bot 51:1371-1379

Travert S, Valerio L, Fourasté Boudet AM, Teuliéres C (1997) Enrichment in specific soluble sugars of two eucalyptus cellsuspension cultures by various treatment enhances their frost tolerance via noncolligative mechanism. Plant Physiol 114:1433-1442

Walck JL, Baskin JM, Baskin CC (1997a) A comparative study of the seed germination biology of a narrow endemic and two geographically-widespread species of Solidago (Asteraceae). 1. Germination phenology and effect of cold stratification on germination. Seed Sci Res 7:47-58

Walck JL, Baskin JM, Baskin CC (1997b) A comparative study of the seed germination biology of a narrow endemic and two geographically-widespread species of Solidago (Asteraceae). 2. Germination responses of buried seeds in relation to seasonal temperature cycles. Seed Sci Res 7:209-220

Weber E (2001) Current and potential ranges of three exotic goldenrods (Solidago) in Europe. Conserv Biol 15:122-128

Weber E (2011) Strong regeneration ability from rhizome fragments in two invasive clonal plants (Solidago canadensis and $S$. gigantea). Biol Invasions 13:2947-2955

Weber W, Jacobs G (2005) Biological flora of Central Europe, Solidago gigantea. Flora 200:109-118

Weber W, Schmid B (1998) Latitudinal population differentiation in two species of Solidago (Asteraceae) introduced into Europe. Am J Bot 85:1110-1121

Weitbrecht K, Müller K, Leubner-Metzger G (2011) First off the mark: early seed germination. J Exp Bot 62:3289-3309

Werner PA, Platt WJ (1976) Ecological relationships of co-occurring goldenrods (Solidago: Compositae). Am Nat 110:959-971

Wu CT, Leubner-Metzger G, Meins FJ, Bradford KJ (2000) Class I $\beta$ 1,3 -glucanase and chitinase are expressed in the micropylar endosperm of tomato seeds prior to radicle emergence. Plant Physiol 126:1299-1313

Yamaguchi S (2008) Gibberellin metabolism and its regulation. Ann Rev Plant Biol 59:225-251

Yuan Y, Wang B, Zhang S, Tang J, Tu C, Hu S, Yong YWH, Chen X (2012) Enhanced allelopathy and competitive ability of invasive plant Solidago canadensis in its introduced range. J Plant Ecol. doi:10.1093/jpe/rts033 